\title{
Fracture and thermal behaviour of biomass ash polypropylene composites
}

\author{
SG Pardo ${ }^{1,2}$, C Bernal ${ }^{3}$, MJ Abad', \\ J Cano' and A Ares'
}

\begin{abstract}
In this work, the fracture and thermal behaviour of environmentally friendly composites based on polypropylene (PP), an olefin block copolymer (OBC) and ash from biomass combustion was investigated. PP/OBC/ash composites with different ash contents and 10 wt\% OBC were prepared by extrusion followed by compression moulding. Ash particles were treated with a silane coupling agent before blending to promote interfacial adhesion between polymer matrix, $\mathrm{OBC}$ and ash. An approach to fracture mechanics was investigated and showed that the fracture parameters increased when OBC was used. Fracture surface analysis by scanning electron microscope revealed that the presence of $O B C$ promotes the material ductile failure and that one of the main failure mechanisms was fibrillised debonding of ash particles encapsulated by OBC from the matrix and its subsequent elongation around them. Free $O B C$ inclusions distributed within the PP matrix would have also induced toughening in the composites investigated. The crystalline state of PP analysed by differential scanning calorimetry is clearly modified by the presence of ash particles, increasing the crystallisation rate and the crystallinity degree of the matrix due to the nucleating effect of the filler. However, the presence of the copolymer counteracted these effects and the PP crystalline state remained practically unchanged in the composites with OBC. Finally, environmentally friendly composites with significantly higher toughness than the matrix or binary PP/ash composites were obtained by introducing an OBC copolymer in the formulation.
\end{abstract}

\footnotetext{
${ }^{1}$ Grupo de Polímeros, Universidade da Coruña (UDC), Ferrol, Spain

${ }^{2}$ Centro Galego do Plástico (CGaP), A Cabana s/n, Ferrol, Spain

${ }^{3}$ Grupo de Materiales Avanzados, INTECIN (UBA-CONICET), Departamento de Ingeniería Mecánica, Buenos Aires, Argentina
}

Corresponding author:

SG Pardo, Grupo de Polímeros, Universidade da Coruña (UDC), Avda 19 de Febrero, 15405 Ferrol, Spain. Email: sgarcia@udc.es 


\section{Keywords}

Fracture, thermal behaviour, polymer composites, polypropylene, ash, polyolefin block copolymer

\section{Introduction}

Over the recent years, many industries have been making significant efforts to reuse their wastes and to produce low-cost composites and ecofriendly designs. A widely used practice in industry to obtain new plastics with better properties is the incorporation of inorganic fillers into polymers.

Ashes have become an attractive alternative for mineral fillers that also meet environmental requirements. ${ }^{1-14}$ They are produced in sufficient quantities and do not imply an unexpected expense. In fact, the cost of ash is lower than that of common mineral fillers and could be very competitive in the industrial market. Ashes are solid industrial wastes produced by the combustion of carbon and other fossil fuels. They are generally mainly composed of a significant amount of silicate oxides and lower contents of metallic oxides.

However, poor interfacial adhesion between inorganic fillers and polymers is often observed. Therefore, different additives, such as coupling agents that are able to react with the filler, are frequently added to the formulations. They have reactive groups compatible with the chemical nature of the polymer and the filler. ${ }^{15,16}$

Silane-type coupling agents are one of the most commonly used coupling agents ${ }^{4}$; these have two kinds of reactive groups in a single molecule. ${ }^{17} \mathrm{~A}$ chemical reaction between the filler functional groups (such as $\mathrm{OH}$ ) and the alkoxy groups of silane is expected to occur during the treatment of the filler, leading to the formation of a silane-functionalised surface. A protective layer capable of avoiding agglomeration of the filler particles is also expected to be created by silane treatment.

The OBC consists of crystallisable ethylene-octene blocks (hard) with very low comonomer content and high melting temperature, alternating with amorphous ethylene-octene blocks (soft) with high comonomer content and low glass transition temperature. Therefore, in thermal studies OBCs show a higher melting temperature than random olefin copolymers with comparable densities. The long ethylene sequences in the hard blocks of OBC could crystallise in lamellar crystals with less defects and higher melting temperature. OBCs exhibit such highly elastomeric performance with polypropylene (PP) blends. ${ }^{18-20}$

The use of elastomers as compatibiliser in polymer composites has also already been reported in the literature for different fibre-reinforced polyolefins. ${ }^{21,22}$

In many applications of polymers, mechanical properties play a significant role and have to be optimised. Hence, vast knowledge of the relationship between morphology and those properties is often required.

In this article, the fracture behaviour of $\mathrm{PP} / \mathrm{OBC} /$ ash composites with different ash content was investigated under quasistatic loading conditions, focusing in identifying the major failure mechanisms operative in these composites. The aim is to establish a 
relationship between morphology and fracture and failure behaviour of these materials. The melting and crystallisation behaviour of the ternary $\mathrm{PP} / \mathrm{OBC} / \mathrm{ash}$ composites in comparison with binary $\mathrm{PP} /$ ash composites previously investigated was also analysed.

\section{Experimental}

\section{Materials and sample preparation}

The ashes used as filler were obtained from biomass combustion. They were kindly supplied by Industrias del Tablero S.A. (INTASA, San Sadurniño, Spain). Ashes were separated using a 400- $\mu \mathrm{m}$ mesh sieve obtaining a size distribution with a mean of 30-40 $\mu \mathrm{m}$ in diameter.

Isotactic PP (PP 070G2 M) delivered by Repsol-YPF (Madrid, Spain), with a melt flow index (MFI) of $12 \mathrm{~g} / 10 \mathrm{~min}\left(230^{\circ} \mathrm{C}, 2.16 \mathrm{~kg}\right)$ and a density of $0.902 \mathrm{~g} / \mathrm{cm}^{3}$ was used as the matrix of the composites.

The OBC (INFUSE ${ }^{\mathrm{TM}}$ D9507.10) used in this study was supplied by The Dow Chemical Company (Freeport, TX, USA). The MFI of OBC was $5 \mathrm{~g} / 10 \mathrm{~min}\left(190^{\circ} \mathrm{C}\right.$, $2.16 \mathrm{~kg}$ ) and density was $0.866 \mathrm{~g} / \mathrm{cm}^{3}$.

A commercially available polymer processing additive (Dynamar FX 5911, Dyneon, 3M Company, Oakdale, MN, USA) was also added in the formulations by $1 \mathrm{wt} \%$ of PP. The blend of PP and Dynamar will be referred to in this work as the PP matrix.

A 0.1-wt\% amino silane coupling agent (GF96 supplied by Wacker-Chemie Italia S.r.L., Milan, Italy) with respect to the weight of ash was incorporated to the filler before blending. The coupling agent was prepared in an aqueous solution at the concentration required and then treated ashes were dried in an oven at $105^{\circ} \mathrm{C}$ for $24 \mathrm{~h}$.

Binary composites were obtained by mixing different contents of ash $(0,10,20$ and $30 \mathrm{wt} \%$ ) and PP in a corotating twin-screw extruder (Brabender DSE20, Duisburg, Germany) operating at a speed of $30 \mathrm{r} / \mathrm{min}$. Barrel and die temperature was $180^{\circ} \mathrm{C}$.

In ternary systems, different amounts of treated ash and $\mathrm{OBC}$ were preextruded under the same processing conditions used for the binary composites. These amounts were chosen to obtain $10 \mathrm{wt} \%$ of OBC and 10, 20 and $30 \mathrm{wt} \%$ of ash in the final formulations. Final ternary $\mathrm{PP} / \mathrm{OBC}$ /ash composites were prepared by adding PP to the OBC/ash blends using the corotating twin-screw extruder (Brabender DSE20) under the same processing conditions.

It is important to note that the silane-treated ash was used in the ternary composite formulations in order to ensure a chemical bonding between ash and the OBC copolymer in the first extrusion step. Hence, treated ash particles remained encapsulated by OBC during the second extrusion step. This core-shell morphology has proved to be the most advantageous for combining good tensile properties with good processability in these composites. ${ }^{23}$

Pellets of the composites were compression-moulded into 3 and $8 \mathrm{~mm}$ plaques at $220^{\circ} \mathrm{C}$, under a pressure of $10 \mathrm{bar}$ for $10 \mathrm{~min}$ followed by $50 \mathrm{bar}$ for $20 \mathrm{~min}$. Then the plaques were rapidly cooled by circulating water within the press plates under a pressure of 50 bar for $25 \mathrm{~min}$. Thermal stresses generated during moulding were released by annealing the plaques in an oven for $3 \mathrm{~h}$ at $100^{\circ} \mathrm{C}$. Table 1 lists the different formulations investigated. 
Table I. Formulations of the PP/ash composites.

\begin{tabular}{lcccc}
\hline Samples & PP $(w t \%)$ & OBC $(w t \%)$ & Ash (wt\%) & Silane (wt\% ash) \\
\hline $100 / 0 / 0$ & 100 & - & - & - \\
$0 / 100 / 0$ & - & 100 & - & - \\
$90 / 10$ & 90 & - & 10 & - \\
$80 / 20$ & 80 & - & 20 & - \\
$70 / 30$ & 70 & - & 30 & - \\
$90 / 10 s$ & 90 & - & 10 & 0.1 \\
$80 / 20 s$ & 80 & - & 20 & 0.1 \\
$70 / 30 s$ & 70 & 10 & 30 & 0.1 \\
$80 / 10 / 10 s$ & 80 & 10 & 10 & 0.1 \\
$70 / 10 / 20 s$ & 70 & 10 & 20 & 0.1 \\
$60 / 10 / 30 s$ & 60 & & 30 & 0.1 \\
\hline
\end{tabular}

PP: polypropylene; OBC: olefin block copolymer.

\section{Fracture characterisation}

Fracture characterisation was carried out on single-edge notched bend (SENB) specimens cut out from compression-molded thick plaques (thickness, $B=8 \mathrm{~mm}$ ). Sharp notches were introduced by sliding a fresh razor blade into a machined slot. Crack-todepth $(a / W)$, thickness-to-depth $(B / W)$ and span-to-depth $(S / W)$ ratios were kept at 0.5 , 0.5 and 4, respectively. Three-point-bend tests were performed in an Instron dynamometer 5566 at $1 \mathrm{~mm} / \mathrm{min}$. Critical stress intensity factor $\left(K_{\mathrm{IQ}}\right)$ and energy release rate $\left(G_{\mathrm{IQ}}\right)$ values at initiation were obtained by following ASTM D-5045-92 standard recommendations. ${ }^{24}$ All tests were performed at room temperature.

As the composites exhibited a controlled propagation way, that is, load did not suddenly drop to zero after the critical load was reached, the work of fracture $\left(W_{\mathrm{f}}\right)$ was also determined in order to characterize the whole fracture behaviour including both the initiation and propagation steps. It was calculated from the total area under the loaddisplacement curve $\left(U_{\mathrm{p}}\right)$ divided by twice the area of the fracture surface (since two new faces are created), as follows ${ }^{25,26}$

$$
W_{f}=U_{\mathrm{p}} / 2 B(W-a)
$$

The work of fracture was defined simply as the total energy consumed to produce a unit area of fracture surface during the 'complete' fracture process. The analysis requires no information on stress intensity at the crack tip, notch tip acuity, the elastic property of the material or its mechanical linearity. ${ }^{25}$ This simple testing and data reduction procedure are motivated by the purpose to compare the performance of different materials.

\section{Fracture surface analysis and study of failure mechanisms}

The fracture surfaces of SENB fracture specimens were examined using a JEOL JSM-6460LV scanning electron microscope (SEM) at an accelerating voltage 
of $20 \mathrm{kV}$. Samples were sputter-coated with a thin layer of gold before they were observed.

To study the dominant failure mechanisms, some SENB specimens were also tested by three-point bending in the Instron dynamometer 5566, at the same speed used in the fracture tests $(1 \mathrm{~mm} / \mathrm{min})$. The specimens were tested up to subcritical displacement levels until some deformation was evident. Side surfaces were previously polished with different abrasive papers of increasing coarseness. Then they were observed by stereo-optical microscopy with a Leica S6D apparatus and by scanning electron microscopy after they were coated with a thin layer of gold. All tests were carried out at room temperature.

\section{Thermal analysis}

Differential scanning calorimetry (DSC) analysis was also performed using a DSC-7 (Perkin Elmer Cetus Instruments, Norwalk, Connecticut, USA) under dry nitrogen atmosphere, at a temperature range of $30-210^{\circ} \mathrm{C}$. Prior to DSC recording, samples were heated to and kept at $210^{\circ} \mathrm{C}$ for $5 \mathrm{~min}$ to erase the influence of any previous thermal histories. Then, they were cooled at a rate of $10^{\circ} \mathrm{C} / \mathrm{min}$ to room temperature and subsequently heated from 30 to $210^{\circ} \mathrm{C}$ at a heating rate of $10^{\circ} \mathrm{C} / \mathrm{min}$. The crystallisation temperature $\left(T_{\mathrm{c}}\right)$ and the enthalpy of crystallisation $\left(\Delta H_{\mathrm{c}}\right)$ were calculated from the cooling scans. The melting temperature $\left(T_{\mathrm{m}}\right)$ and the heat of melting $\left(\Delta H_{\mathrm{m}}\right)$ were measured in the last scan. The crystallinity degree $(\alpha)$ was calculated based on the relationship $\alpha=\left(\Delta H / \Delta H_{0}\right) \times 100$, assuming $\Delta H_{0}=195 \mathrm{~J} / \mathrm{g}$ for $100 \%$ crystalline $\mathrm{PP}^{27}$

\section{Results and discussion}

\section{Fracture behaviour}

Figure 1 shows load-displacement curves obtained in quasistatic three-point-bending tests for the $\mathrm{PP} / \mathrm{OBC} /$ ash composites investigated. All PP/OBC/ash composites displayed ductile fracture with stress-whitened fracture surfaces. In fact, the area under load-displacement curves is significantly larger than that of the binary PP/ash composites reported in a previous work. ${ }^{28}$

According to linear elastic fracture mechanics, ${ }^{29,30}$ for valid plane strain fracture toughness determinations, linear-elastic behaviour up to the point of fracture and plane strain conditions are simultaneously required. Although these requirements were not satisfied in our experiments, the initiation parameter values still reflect a critical state for crack initiation. ${ }^{31}$ Therefore, they were used here to compare the fracture initiation behaviour of the materials. In addition, as the composites exhibited a controlled propagation way, the work of fracture parameter was also determined to characterize the complete fracture process including both initiation and propagation steps.

Values of the fracture parameters $\left(K_{\mathrm{IQ}}, G_{\mathrm{IQ}}\right.$ and $\left.W_{\mathrm{f}}\right)$ are listed in Table 2 along with their deviations. Fracture parameter values for the binary composites as reported previously by Pardo et al. ${ }^{28}$ are also included in Table 2 for comparison. As observed in this table, the incorporation of the OBC copolymer to PP led to improved fracture behaviour in comparison with the PP matrix or the binary PP/ash composites. 


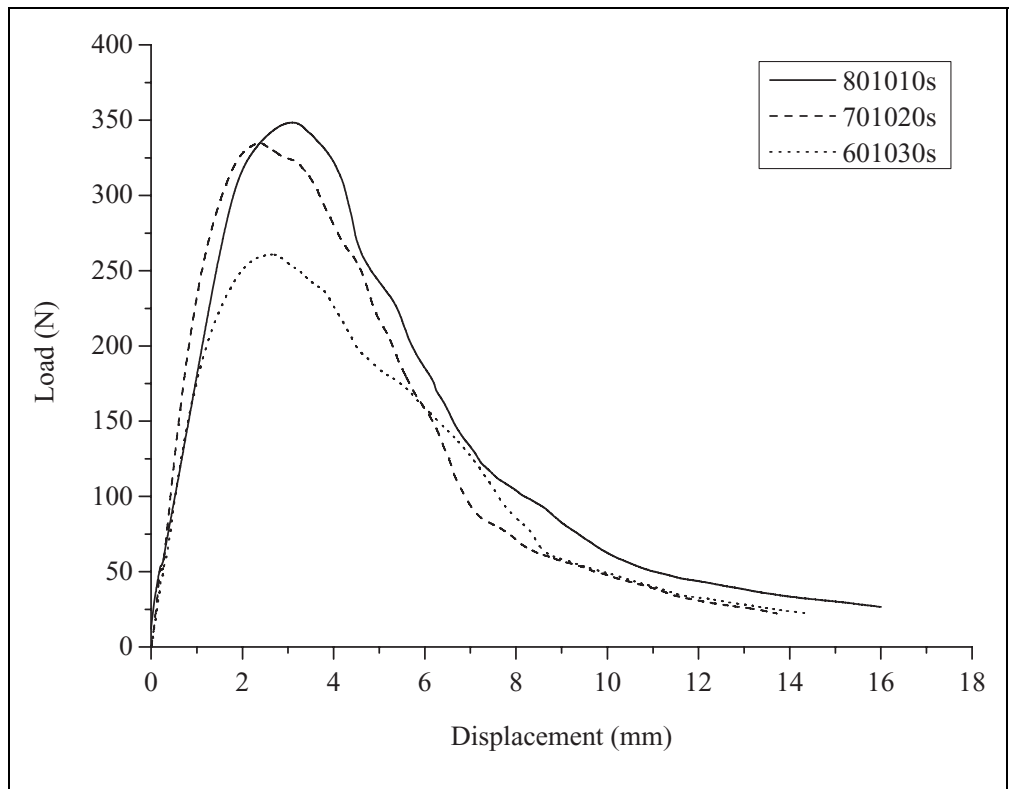

Figure I. Load versus displacement curves obtained in fracture tests for the investigated ternary PP/OBC/ash composites.

PP: polypropylene; OBC: olefin block copolymer.

Table 2. Fracture parameters for the PP/OBC/ash composites.

\begin{tabular}{lccr}
\hline Samples & $K_{\mathrm{IQ}}\left(\mathrm{MPa} \mathrm{m}^{1 / 2}\right)$ & $G_{\mathrm{IQ}}\left(\mathrm{kJ} / \mathrm{m}^{2}\right)$ & $\mathrm{Wf}\left(\mathrm{kJ} / \mathrm{m}^{2}\right)$ \\
\hline $100 / 0 / 0$ & $1.37 \pm 0.13$ & $3.66 \pm 0.40$ & $2.17 \pm 0.31$ \\
$90 / 10$ & $2.93 \pm 0.11$ & $7.09 \pm 0.29$ & $5.09 \pm 0.30$ \\
$80 / 20$ & $2.84 \pm 0.11$ & $5.96 \pm 0.12$ & $4.10 \pm 0.15$ \\
$70 / 30$ & $2.70 \pm 0.09$ & $5.22 \pm 0.19$ & $3.63 \pm 0.24$ \\
$90 / 10 \mathrm{~s}$ & $3.13 \pm 0.14$ & $7.98 \pm 0.67$ & $5.97 \pm 0.43$ \\
$80 / 20 \mathrm{~s}$ & $3.02 \pm 0.43$ & $6.26 \pm 0.27$ & $4.65 \pm 0.31$ \\
$70 / 30 \mathrm{~s}$ & $2.72 \pm 0.06$ & $6.03 \pm 0.20$ & $4.32 \pm 0.13$ \\
$80 / 10 / 10 \mathrm{~s}$ & $3.25 \pm 0.49$ & $21.65 \pm 5.36$ & $13.67 \pm 1.74$ \\
$70 / 10 / 20 \mathrm{~s}$ & $3.06 \pm 0.95$ & $10.99 \pm 2.86$ & $10.04 \pm 1.74$ \\
$60 / 10 / 30 \mathrm{~s}$ & $2.00 \pm 0.28$ & $12.77 \pm 2.01$ & $7.92 \pm 2.73$
\end{tabular}

PP: polypropylene; OBC: olefin block copolymer.

In addition, a decreasing trend of the fracture toughness parameters with increasing ash content was observed (Table 2) probably due to the increase in the number of critical-size flaws that induced premature failure. However, all composites displayed higher critical initiation values than the matrix as a result of the toughening mechanism induced by the presence of ash and OBC. 
Also note that the improvement observed in the case of the fracture energy of the $\mathrm{PP} / \mathrm{OBC} /$ ash composites, as reflected by both the critical initiation value $\left(G_{\mathrm{IQ}}\right)$ and the work of fracture value ( $W_{\mathrm{f}}$; Table 2 ) is remarkable, as much more energy was absorbed by these composites. To induce matrix stretching around filler particles and debonding at the interfaces, a weak adhesion between polymer matrix and filler is needed. These mechanisms are confirmed during image analysis by SEM. This mechanism required a large amount of energy. ${ }^{32,33}$ As mentioned in a previous article, ${ }^{23}$ the copolymer transformed rigid ash particles into soft particles with a hard core and a soft shell. Because of this, the particles can better absorb the energy and the material toughness increases. On the other hand, a part of the OBC segregated as almost spherical inclusions within the continuous PP matrix and around the ash particles, which have also contributed to toughening. These two effects make ternary composites to absorb significantly higher deformation energy than binary composites as reflected by the energy release rate $\left(G_{\mathrm{IQ}}\right)$ and work of fracture $\left(W_{\mathrm{f}}\right)$ values.

The differences in toughness values for the different ternary composites may also be explained by the fact that the same amount of OBC was used to coat more ash particles. With 20 and $30 \mathrm{wt} \%$ of ash, a lower number of copolymer inclusions are found within the matrix ${ }^{23}$ because the amount of free $\mathrm{OBC}$ is lower.

It is worth noting that although the energy release rate at initiation falls $50 \%$ with an OBC: ash ratio of $1: 2$ with respect to the $80 / 10 / 10$ s composite, the decrease in the $W_{\mathrm{f}}$ value is much lower. This suggests that a significant part of the total energy might be absorbed during the propagation stage and this is also in agreement with tensile results. In tensile tests, the composites with an OBC:ash ratio of 1:2 displayed the highest elongation at break while maintaining the stiffness value. ${ }^{23}$

\section{Failure mechanisms}

Scanning electron micrographs of the fracture surfaces of $\mathrm{PP} / \mathrm{OBC} / \mathrm{ash}$ specimens are presented in Figure 2. As observed in this figure, composites with $\mathrm{OBC}$ exhibited ductile behaviour; ductile tearing of the PP matrix is clearly seen in all micrographs. This ductile tearing is greater than that observed in the PP/ash composites without OBC previously investigated. ${ }^{28}$ It is also seen in Figure 2 that there are many ash particles with different size and shape. This figure also clearly shows that the particles debonded from the PP matrix, which elongated around them. Furthermore, there are evidences of OBC inclusions into PP matrix, as explained by Ana et al. ${ }^{23}$ This failure mechanism was previously observed in binary PP/ash composites and was originally proposed by Kim and Michler ${ }^{34,35}$ for particle-filled semicrystalline polymers and later observed by others $^{32,33,36,37}$ for different PP composites. In addition, note that ash particles appear encapsulated by $\mathrm{OBC}$, as previously reported ${ }^{23}$ and that fibrillation occurs through the OBC layer that covers ash particles.

A more detailed view of the SEM image of the 70/10/20s composite in Figure 3 shows how fibrils of $\mathrm{OBC}$ are formed around ash particles. This figure also presents a porous and hard ash particle, where the layer of $\mathrm{OBC}$ is introduced into the particle. Despite prior initiation of particle debonding, these fibrils allow stress transfer between the matrix and the filler. Thus, the copolymer creates a soft interface for stress transfer. 

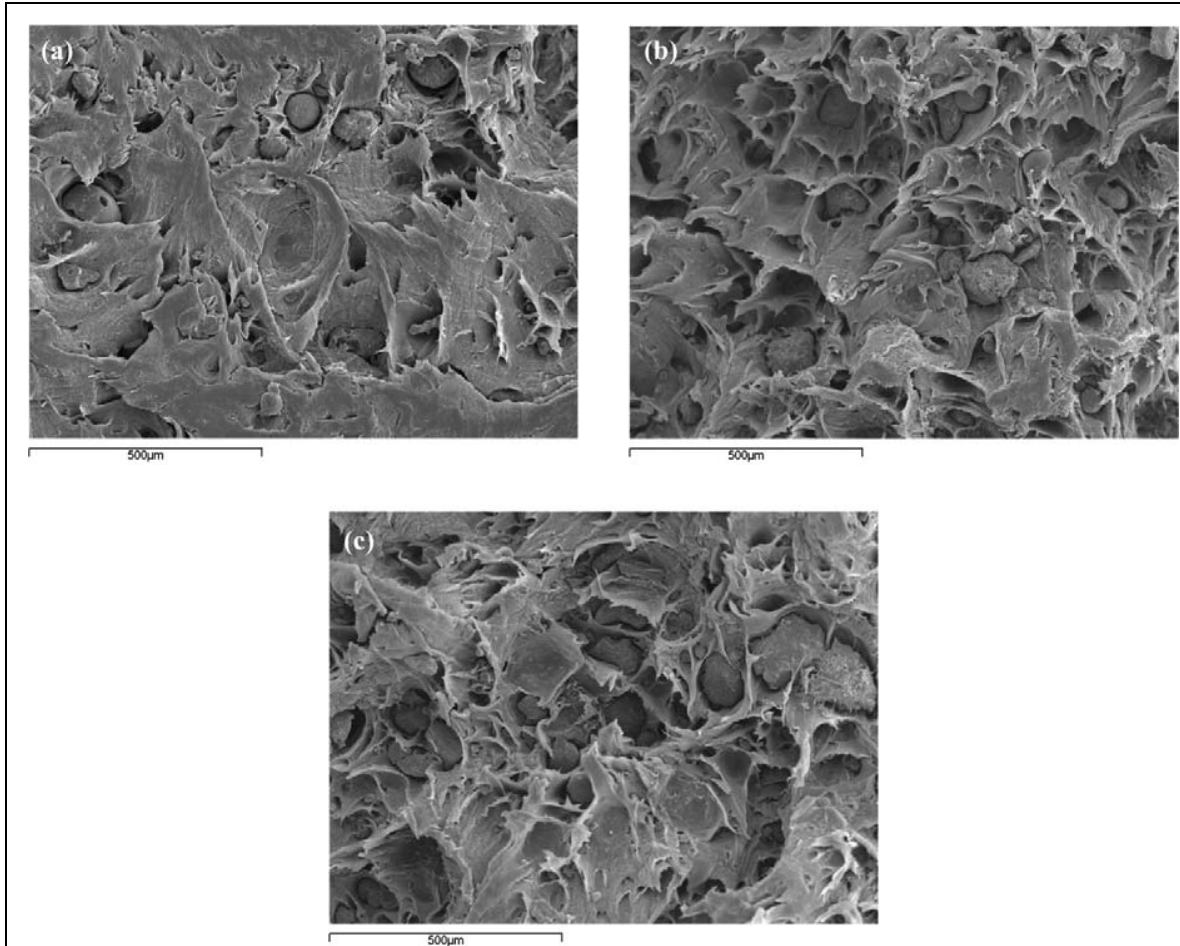

Figure 2. Scanning electron micrographs for the different PP/OBC/ash composites investigated. (a) $80 / 10 / 10$, (b) 70/10/20 and (c) 60/10/30.

PP: polypropylene; OBC: olefin block copolymer.

The ash particles are coated with a thin and soft copolymer layer that can be deformed plastically, and OBC fibrils are stretched between filler particles and the PP matrix. These fibrils seem to have been formed at some stage of the deformation process, and their orientation created a plastic deformation zone. In addition, SEM fractographs revealed how $\mathrm{PP}$ and $\mathrm{OBC}$ act like a single matrix. Although it is known that $\mathrm{OBC}$ inclusions exist within the PP matrix, they cannot be distinguished in Figure 3 due to the extensive ductile tearing and stretching that occur in our composites.

A scanning electron micrograph of a typical side view of a composite SENB sample tested until some damage was developed is shown in Figure 4. The particles debonded from the matrix, which also elongated around them. OBC fibrils are also clearly seen in the middle of Figure 4.

The main aim of OBC incorporation is to enhance toughening as a result of a better composite morphology. Some adhesion between the silane-modified ash particles and the matrix seems to exist, deformation occurring through a debonding process with fibrillisation at the interface between $\mathrm{OBC}$-encapsulated ash particles and matrix. In the first stage, stress concentration occurs around these particles and they are slightly 


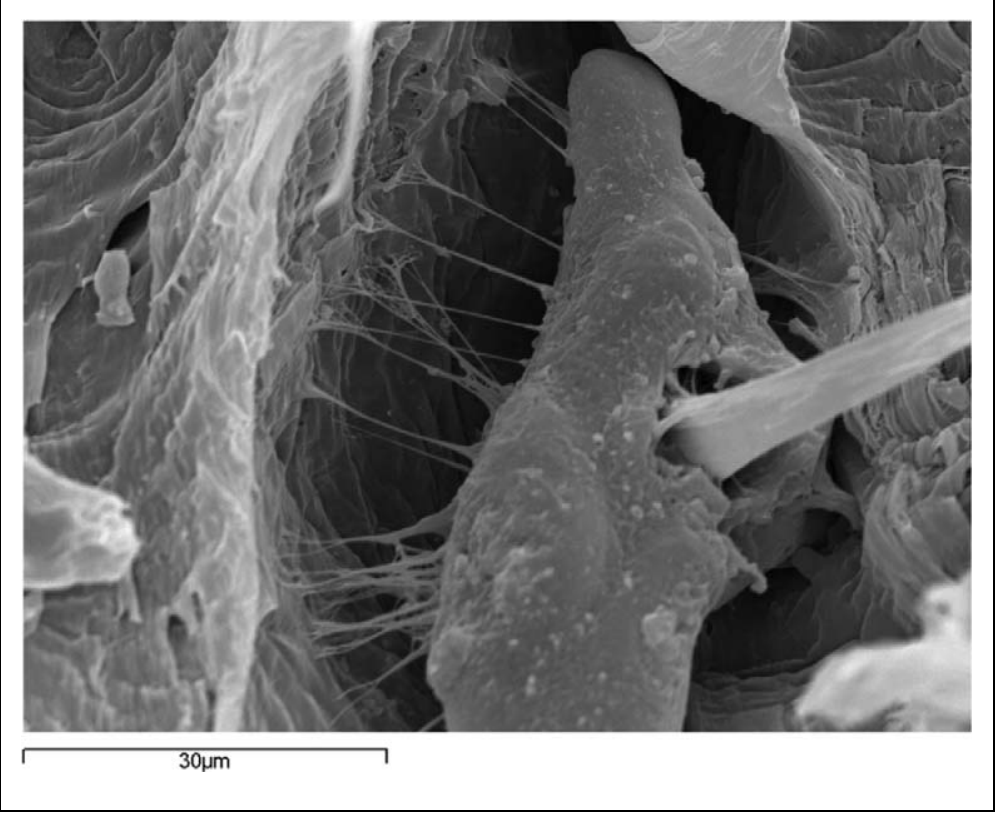

Figure 3. Closer view of Figure 2(b).

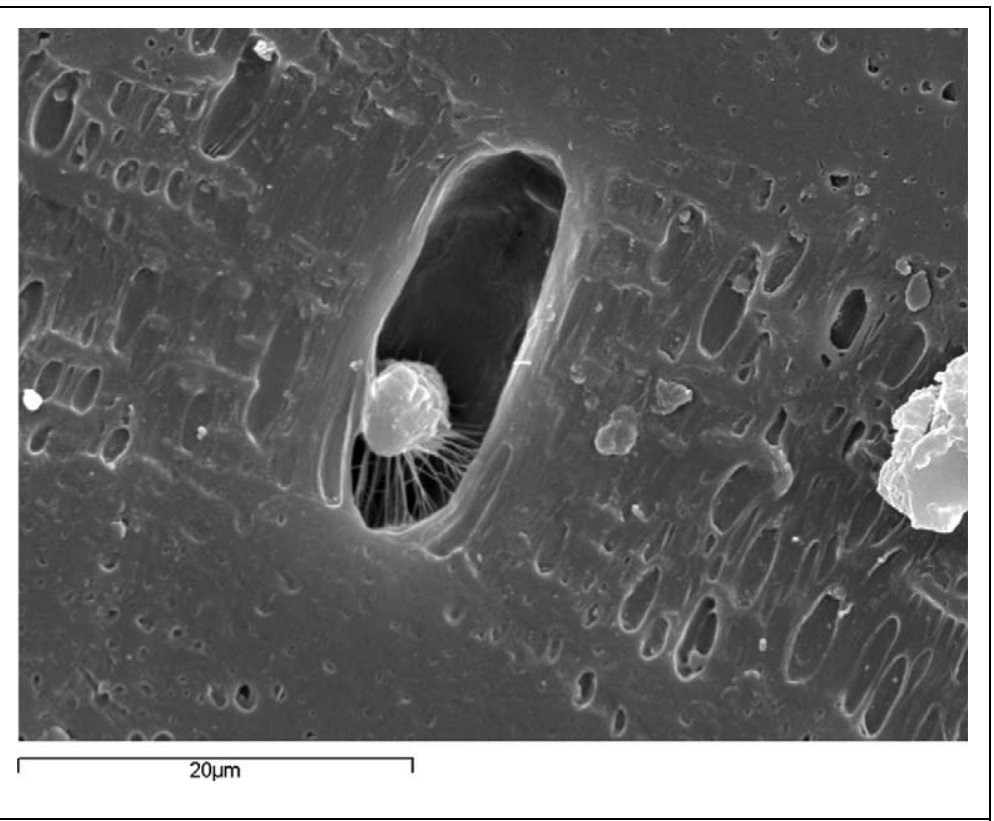

Figure 4. SEM image of a lateral view of a SENB sample of $80 / 10 / 10$ s at $\times 2500$. SEM: scanning electron microscope; SENB: single-edge notched bend. 

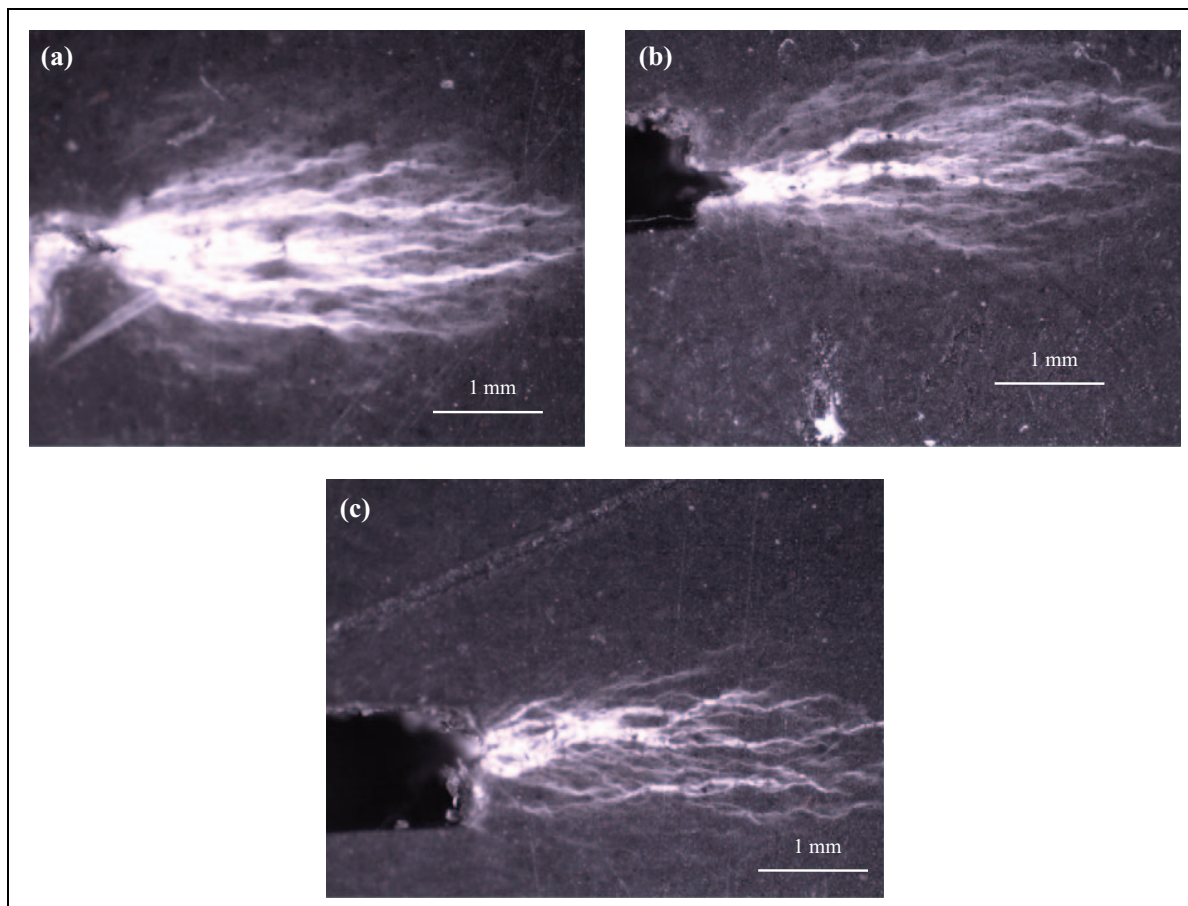

Figure 5. OM images of lateral views of SENB samples. (a) $80 / 10 / 10$ s, (b) $70 / 10 / 20$ s and (c) $60 / 10 /$ $30 \mathrm{~s} \times 20$.

OM: optical microscopy; SENB: single-edge notched bend.

stretched or deformed. Due to the existence of some interfacial adhesion, fibrils are formed within the OBC layer, which covers the ash particles and PP and simultaneously shear bands appear in the matrix. A rich $\mathrm{OBC}$ matrix region is formed around the ash particles (like a core-shell structure) and its deformability stimulates the increase in fibrils. By increasing the deformation process, the fibrils formed at the polar regions of the particles break down, and only a few fibrils remain at the equator of the particles. In the last stage, further shear flow of the matrix is considerably enhanced. So, a fibrillised debonding process at the interface may be one of the major toughening mechanisms as a result of a core-shell structure. ${ }^{23,35}$ Even so, the presence of critical large ash particles still leads to the decrease in the fracture parameter values with ash content. ${ }^{28,38,39}$

Images of side views obtained by optical microscopy (Figure 5) also confirmed that the damage zone is smaller as the ash content is higher. This result is in agreement with the curves obtained in fracture tests, where the area under the load-displacement curve decreases as the ash content increases (Figure 1) and with the decreasing trend of fracture parameters with filler loading observed. It is also important to note that no damage zone was seen in the side views of the binary PP/ash composites, in agreement with the significantly lower toughness values exhibited by these materials. ${ }^{28}$ 
Table 3. Thermal data measured by the differential scanning calorimetric scans for the different composites.

\begin{tabular}{lrcccccc}
\hline Samples & $T_{\mathrm{C}}$ & $\Delta H_{\mathrm{C}}\left(\mathrm{J} / \mathrm{g}_{\mathrm{PP}}\right)$ & $\alpha(\%)$ & $T_{\mathrm{ml}}$ & $T_{\mathrm{m} 2}$ & $\Delta H_{\mathrm{m}}\left(J / g_{\mathrm{PP}}\right)$ & $\alpha(\%)$ \\
\hline $100 / 0 / 0$ & 116.5 & 108.4 & 55.6 & & 166.1 & 99.8 & 51.2 \\
$0 / 100 / 0$ & 96.5 & $29.6^{\mathrm{a}}$ & - & 122.7 & - & $22.0^{\mathrm{a}}$ & - \\
$90 / 10$ & 121.1 & 97.3 & 49.9 & & 164.3 & 82.1 & 42.1 \\
$80 / 20$ & 120.8 & 112.6 & 57.7 & & 164.0 & 91.9 & 47.1 \\
$70 / 30$ & 121.5 & 119.0 & 61.0 & & 164.2 & 95.2 & 48.8 \\
$90 / 10 \mathrm{~s}$ & 121.5 & 105.9 & 54.3 & & 164.3 & 91.2 & 46.8 \\
$80 / 20 \mathrm{~s}$ & 122.0 & 104.3 & 53.5 & & 165.0 & 88.0 & 45.1 \\
$70 / 30 \mathrm{~s}$ & 122.3 & 119.5 & 61.3 & & 165.2 & 98.7 & 50.6 \\
$80 / 10 / 10 \mathrm{~s}$ & 117.2 & 125.5 & 64.2 & 125.6 & 164.8 & 89.5 & 45.9 \\
$70 / 10 / 20 \mathrm{~s}$ & 118.7 & 127.3 & 65.3 & 124.7 & 166.1 & 97.8 & 50.2 \\
$60 / 10 / 30 \mathrm{~s}$ & 117.5 & 140.3 & 71.9 & 123.7 & 163.9 & 103.1 & 52.8 \\
\hline
\end{tabular}

${ }^{\mathrm{a} E n t h a l p y}(\mathrm{~J} / \mathrm{gOBC})$.

Further work is in progress to study in more detail the toughening mechanism induced by the free $\mathrm{OBC}$ inclusions and its contribution to the overall toughening.

\section{Thermal analysis}

Table 3 summarises the data obtained for the cooling thermograms and subsequent heating scans for neat polymers and the PP/OBC/ash composites investigated. Thermal analysis of binary PP/ash composites was also performed and the results obtained were also included in Table 3 for comparison. The crystallisation temperatures $\left(T_{\mathrm{c}}\right)$ of PP and $\mathrm{OBC}$ are close to each other; therefore, a single exothermic peak during the cooling scan is observed for the composites. In these cases, the crystallisation enthalpy of PP was measured as the area of the exothermic peak. For the ternary formulations, a small portion of the peak enthalpy corresponds to $\mathrm{OBC}$ crystallisation, but it can be considered negligible because the crystallisation enthalpy for the raw copolymer is much lower (about $29.6 \mathrm{~J} / \mathrm{g}$ ) than that of the PP (about $108.4 \mathrm{~J} / \mathrm{g}$ ), especially taking into account the low amount of $\mathrm{OBC}$ used in the composite formulations with respect to the PP content. Besides, the ternary samples have the same OBC content; hence, the data trend can be considered valid.

In the binary composites, the crystallisation temperature $\left(T_{\mathrm{c}}\right)$ increases with filler addition. The crystallisation peak of PP was shifted to higher temperatures, suggesting that the crystallisation of PP started earlier and ash acted as nucleating agent increasing the crystallisation rate. The nucleation effect is similar when ash treated with silane is incorporated into the composites. This is in agreement with the results of Bartczak et al., ${ }^{40}$ who reported the influence of the filler on the nucleation of crystallites of PP by increasing the crystallisation temperature. This effect is also noticeable in the degree of crystallisation of binary samples without coupling agent. It increased proportionally with ash content and except in the 90/10 sample, crystallinity was higher than that of raw PP. 
The presence of solid surfaces seems to reduce free enthalpy for critical nucleation and promote PP crystallinity. This fact could be related with the increase in composite stiffness as a function of filler content observed in tensile tests and reported in a previous investigation. ${ }^{23}$

For the composites with treated ash, the degree of crystallinity was similar to that of the PP matrix. This can be attributed to the decreased nucleating effect of the ash surface as a result of the treatment with silane. Furthermore, the excess silanols in the samples may be crosslinked, hindering PP chain motion and reducing its crystallinity. The two effects, the nucleating effect of ash particles and the reduction of chain motion due to crosslinking, are competitive and overcome one or another depending on ash content. It was observed that with 10 and $20 \mathrm{wt} \%$ of treated ash, the crystallinity degree is similar to that of raw PP. But with $30 \mathrm{wt} \%$ ash, the nucleating effect of the filler increases the crystallinity degree, although the ash was treated with silane.

During the heating scans of the binary samples, the PP melting temperature $\left(T_{\mathrm{m} 2}\right)$ slightly decreased with respect to the value of raw PP. Hence, the obtained PP crystallites are smaller or less perfect, probably because they are formed around the filler particles and as a result alter the structure of the sample. The size of ash particles can also influence the morphology of the crystalline state. ${ }^{41,42}$ In our case, the size distribution of filler particles is quite broad, probably promoting a heterogeneous crystalline state in the PP with different sizes and perfection in the crystallites.

The crystallinity degree calculated from the melting enthalpy follows the same trend as the values measured in the cooling scans for the binary samples. The absolute values of crystallinity in the melting scans are lower than those of the cooling scans, which can be attributed to the difficulty in drawing a correct base line and to the unavoidable errors in the area integration process.

For the ternary composites, $T_{\mathrm{c}}$ remained without variations with respect to the value for PP. The nucleating effect of ash seems to be counteracted by the presence of OBC. Other authors have shown that the crystallisation temperature of PP decreases in blends with olefinic-copolymers (like OBC). ${ }^{43}$ The reason is that the olefinic block tends to diffuse into the PP matrix and can hinder access of PP chains to the arrangement and growth of nuclei, resulting in a less crystalline matrix. The effect is more pronounced when the $\mathrm{OBC}$ :ash ratio is $1: 1$, because the amount of ash is low and there is more free $\mathrm{OBC}$, not associated to ash particles, forming microdomains in the PP matrix. For the other OBC:ash ratios, 1:2 and 1:3, the $\mathrm{OBC}$ is mainly placed around ash particles and affects crystallinity of PP at the interfacial regions. The decrease in the $T_{\mathrm{c}}$ values is minor or even disappears in these cases.

Figure 6 shows the DSC endotherms for the different PP/OBC/ash composites. For ternary samples, the heating scans displayed curves with two melting peaks. Measured melting temperatures $\left(T_{\mathrm{m} 1}\right.$ and $\left.T_{\mathrm{m} 2}\right)$ correspond to $\mathrm{OBC}$ (around $125^{\circ} \mathrm{C}$ ) and $\mathrm{PP}$ (around $166^{\circ} \mathrm{C}$ ), respectively. These temperature values practically remained constant with ash content, suggesting that neither $\mathrm{OBC}$ nor PP changed in the polymorphous crystalline type.

For the ternary composites melting behaviour, the same trend of the cooling curves was observed: the heating scan of 80/10/10s composite (OBC:ash ratio of 1:1) clearly shows the $\mathrm{OBC}$ melting peak, but it is less pronounced when the $\mathrm{OBC}$ :ash ratio 


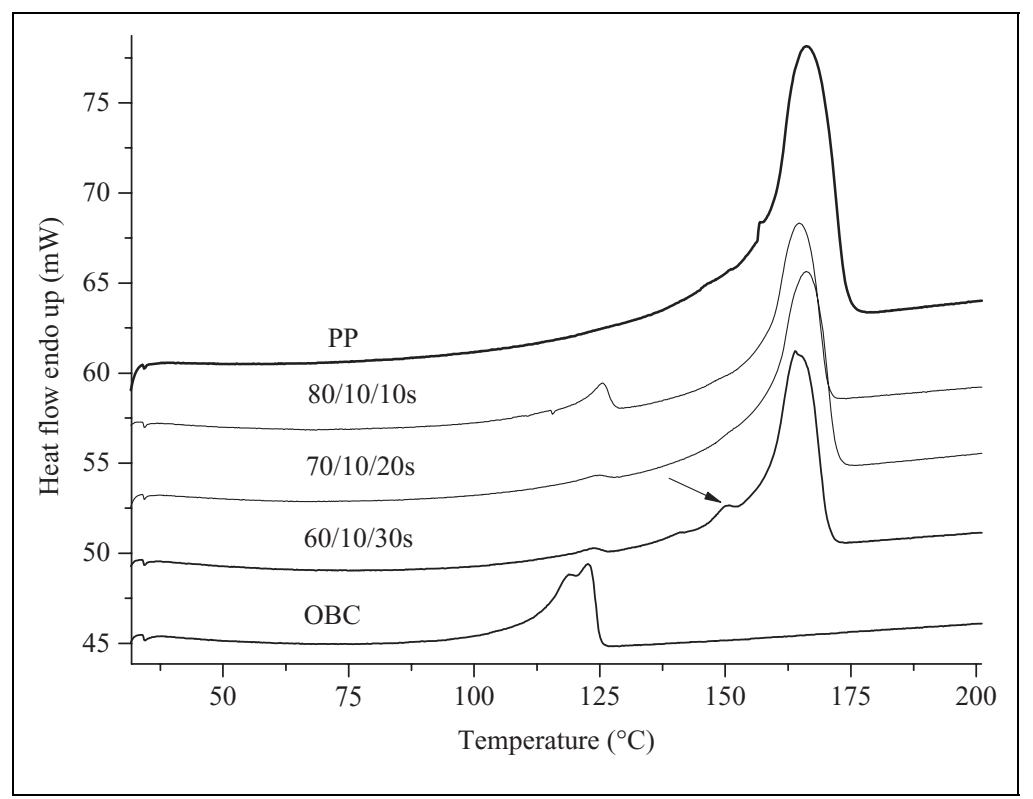

Figure 6. DSC thermograms for neat polymers and the PP/OBC/ash composites obtained in the heating scans.

DSC: differential scanning calorimetry; PP: polypropylene; OBC: olefin block copolymer.

decreases. In the first case, there is enough free OBC able to crystallise into different PP structures to give a clear peak. When the OBC:ash ratio decreases, the peak also decreases or almost disappears, showing that the amount of free $\mathrm{OBC}$ is lower. The crystallinity degree of PP measured in the heating scans confirms that the lowest value corresponds to the $80 / 10 / 10$ s composite. For the other ternary composites, the crystallinity degree is similar to that of raw PP.

The nucleating effect of ash particles observed in the binary composites is counteracted by the presence of the copolymer, because access of the PP chains to the ash surface is blocked by the OBC layer, hindering their function as nucleation sites.

It is worth commenting that the curve for the 60/10/30s composite shows a shoulder centred at $150^{\circ} \mathrm{C}$ (Figure 6), which indicates that the crystalline structure of PP has a small $\beta$ polymorphous portion, as also observed previously by other authors. ${ }^{38,39}$ These authors proved that the particle surfaces of rigid fillers can act as nucleation site for $\beta$ crystals. More recently, Nath et al. ${ }^{4,45}$ have confirmed how coal fly ashes (obtained from coal thermal plants) have acted as heterogeneous $\beta$-nucleating agents inducing a secondary $\beta$-crystalline phase in PP/ash composites when a higher amount of ash was used.

\section{Conclusions}

The fracture and failure behaviour of ternary $\mathrm{PP} / \mathrm{OBC} /$ ash composites with different ash contents was investigated under quasistatic loading conditions. 
The ternary composites displayed higher toughness values $\left(K_{\mathrm{IQ}}\right)$ than the PP matrix. Moreover, fracture energy at initiation and work of fracture $\left(G_{\mathrm{IC}}\right.$ and $\left.W_{\mathrm{f}}\right)$ values were significantly improved for these composites in comparison with the matrix and the binary composites without $\mathrm{OBC}$ previously investigated. ${ }^{24}$ This can be attributed to the synergistic effect of the toughening induced by the presence of ash particles encapsulated by the $\mathrm{OBC}$ copolymer and by the free $\mathrm{OBC}$ inclusions within the PP matrix. However, by increasing the filler amount, the number of particles with a critical size grows and hence, reduced toughness was observed with filler loading. It seems that the number of $\mathrm{OBC}$-encapsulated ash particles effective for toughening and of free $\mathrm{OBC}$ inclusions is not enough to counteract that effect.

Fracture surface analysis by SEM also revealed that the presence of $\mathrm{OBC}$ promotes the material ductile failure and that one of the main failure mechanisms was debonding of OBC-covered ash particles from the matrix and its subsequent elongation around them. A fibrillised debonding process at the interface was occurring as a result of the core-shell morphology. This morphology can favour the deformation process and therefore the fracture energy can be improved during the failure process. In addition, free $\mathrm{OBC}$ inclusions within the PP matrix would have also contributed to the materials toughening.

The crystallisation and melting behaviour of both binary PP/ash composites and ternary $\mathrm{PP} / \mathrm{OBC} / \mathrm{ash}$ composites was also investigated. In the binary composites, the crystalline state of PP is clearly modified by the presence of ash particles, increasing the crystallisation rate and the crystallinity degree due to the nucleating effect of the filler. This effect is more noticeable for particles without treatment.

With OBC incorporation, the nucleating effect of ash is reduced because PP chain access to the ash surface is blocked by the OBC layer which covers ash particles, hindering their role as nucleation sites. In addition, the OBC copolymer can diffuse into the PP matrix making the arrangement of PP chains more difficult. This last effect is more pronounced at the 1:1 OBC:ash ratio, with higher content of free OBC.

In summary, the sample with an OBC:ash ratio of 1:1 presents a core-shell morphology where ash particles are well dispersed and it also has some inclusions of free $\mathrm{OBC}$ in the PP matrix. This sample morphology presents the best fracture properties under quasistatic loading conditions. Besides, for this formulation, the crystalline state of PP remained practically unchanged despite the $\mathrm{OBC}$ and the silane treatment of ash used. This is a desirable effect for potential industrial applications of this material by injection moulding.

Finally, environmentally friendly composites with significantly higher toughness than the matrix or binary $\mathrm{PP} /$ ash composites were obtained by introducing an $\mathrm{OBC}$ copolymer in the formulation.

\section{Funding}

The financial support was provided to Xunta de Galicia-FEDER (Program of Consolidation and Structuring Competitive Research Units (CN2011/008)).

\section{References}

1. Bose S and Mahanwar PA. Effect of flyash on the mechanical, thermal, dielectric, rheological and morphological properties of filled nylon 6. J Min \& Mat Charact \& Eng 2004; 3: 65-72. 
2. Stefani PM, Cyras V, Tejeira Barchi A and Vazquez A. Mechanical properties and thermal stability of rice husk ash filled epoxy foams. J Appl Polym Sci 2006; 99:2957-2965.

3. Stefani PM, García D, Lopez J and Jiménez A. Thermogravimetric analysis of composites obtained from sintering of rice husk-scrap tire mixtures $J$ Therm Anal Cal 2005; 81: 315-320.

4. Chaudhary DS, Jollands MC and Cser F. Recycling rice hull ash: another filler material for polymeric composites? Adv Polym Tech 2004; 23: 147-155.

5. Wang M, Shen Z, Cai C, Ma S and Xing Y. Experimental investigations of polypropylene and poly(vinyl chloride) composites filled with plerospheres. J Appl Polym Sci 2004; 92: 126-131.

6. Siriwardena S, Ismail $\mathrm{H}$ and Ishiaku US. Effect of mixing sequence in the preparation of white rice husk ash filled polypropylene/ethylene-propylene-diene monomer blend Polym Test 2000; 20: 105-113.

7. Siriwardena S, Ismail $\mathrm{H}$ and Ishiaku US. A comparison of the mechanical properties and water absorption behavior of white rice husk ash and silica filled polypropylene composites $J$ Reinf Plast Comp 2003; 22: 1645-1667.

8. Ismail H, Hong HB, Ping CY and Abdul Khalil HPS. The effects of a compatibilizer on the properties of polypropylene/silica/white rice husk ash hybrid composites J Reinf Plast Comp 2002; 21: 1685-1712.

9. Kruger RA, Hovy M and Wardle D. The use of fly ash filler in rubber. In: Proceedings of international ash utilization symposium, paper no. 72. Lexington, KY, USA, 18-20 October 1999.

10. Hwang JY. Beneficial use of fly ash, national energy technology department. In: Proceedings of the 13th US/Korea Workshop on Energy \& Environment Reno (NV) USA, September 1999. pp. 373-396. US Department of Energy. http://www.netl.doe.gov/ (accessed 11 July 2012).

11. Chand N and Vashishtha SR. Melt flow studies of fly ash particulate filled PP/PMMA blend. Clay Res 2000; 19: 49-56.

12. Keya D, Dipa R, Kuntal A, Bandyopadhyay NR, Mohanty AK and Manjusri M. Development of recycled polypropylene matrix composites reinforced with fly ash. J Reinf Plast Comp 2009; 29: 510-517.

13. Chand $\mathrm{N}$ and Khare N. Effect of fly ash loading on dielectric relaxation of polypropylene/low density polyethylene blends. Met Mater Process 2000; 12: 319-326

14. Deepthi MV, Madan S, Sailaja RRN, Anantha P, Sampathkumaran P and Seetharamu S. Mechanical and thermal characteristics of high density polyethylene-fly ash Cenospheres composites. Mater Des 2010; 31: 2051-2060.

15. Pionteck J, Sadhu VB, Jakisch L, Pötschke P, Häubler L and Janke A. Crosslinkable coupling agents: synthesis and use for modification of interfaces in polymer blends. Polymer 2005; 46: 6563-6574.

16. Thongsang $\mathrm{S}$ and Sombatsompop N. Effect of $\mathrm{NaOH}$ and $\mathrm{Si} 69$ treatments on the properties of fly ash/natural rubber composites. Polym Compos 2006; 27: 30-40.

17. Pardo SG, Bernal C, Ares A, Abad MJ and Cano J. Rheological, thermal, and mechanical characterization of fly ash-thermoplastic composites with different coupling agents. Polym Compos 2010; 31: 1722-1730.

18. Liu G, Zhang X, Liu C, Chen H, Walton K and Wang D. Morphology and mechanical properties of binary blends of polypropylene with statistical and block ethylene-octene copolymers. J Appl Polym Sci 2011; 119: 3591-3597.

19. Steve Chum $P$ and Swogger Kurt W. Olefin polymer technologies history and recent progress at the Dow chemical company. Prog Polym Sci 2008; 33(8): 797-819. 
20. Liu G, Zhang X, Li X, Chen H, Walton K and Wang D. Correlation of miscibility and mechanical properties of polypropylene/olefin block copolymers: effect of chain composition. $J$ Appl Polym Sci 2012; 125: 666-675.

21. Oksman K and Lindberg H. Influence of thermoplastic elastomers on adhesion in polyethylene wood flour composites. J Appl Polym Sci 1998; 68: 1845-1855.

22. Xi XL, Fung KL, Li RKY, Tjong SC and Mai YW. Structural and mechanical behavior of polypropylene/ maleated styrene-(ethylene-co-butylene)-styrene/sisal fiber composites prepared by injection molding. J Polym Sci Part B Polym Phys 2002; 40: 1214-1222.

23. Ana A, Santiago GP, Abad MJ, Jesús C and Luis B. Effect of aminomethoxy silane and olefin block copolymer on rheomechanical and morphological behavior of fly ash-filled polypropylene composites. Rheol Acta 2010; 49: 607-618

24. ASTM. Standard test methods for plane strain fracture toughness and energy release rate determination of plastics materials; ASTM D5045-93. New York, NY: American Society for Testing and Materials, 1993.

25. Aksel C and Warren PD. Work of fracture and fracture surface energy of magnesia-spinel composites. Compos Sci Technol 2003; 63: 1433-1440.

26. Nuñez AJ, Aranguren MI and Berglund LA. Toughening of wood particle composites effects of sisal fibers. J Appl Polym Sci 2006; 101: 1982-1987

27. Fatou JG. Melting temperature and enthalpy of isotactic polypropylene. Eur Polym J 1971; 7: $1057-1064$.

28. Pardo SG, Bernal C, Abad MJ, Cano J and Barral L. Deformation and fracture behavior of PP/ ash composites. Compos Interface 2009; 16: 97-114.

29. Wong SC and Mai YW. Effect of rubber functionality on microstructures and fracture toughness of impact-modified nylon 6,6/polypropylene blends: 1 . Structure property relationships. Polymer 1999; 40: 1553-1566.

30. Williams JG. Fracture mechanics of polymers. London, UK: Ellis Horwood Limited, 1984.

31. Gensler R, Plummer CJG, Grein C and Kausch HH. Influence of the loading rate on the fracture resistance of isotactic polypropylene and impact modified isotactic polypropylene. Polymer 2000; 41: 3809-3819.

32. Vu-Khanh T and Fisa B. Effects of fillers on fracture performance of thermoplastics: strain energy density criterion. Theor Appl Fracture Mech 1990; 13: 11-19.

33. Vu-Khanh T and Fisa B. Fracture behavior of mica-reinforced polypropylene: effects of coupling agent, flake orientation, and degradation. Polym Compos 1986; 7: 219-226.

34. Kim GM and Michler GH. Micromechanical deformation processes in toughened and particlefilled semicrystalline polymers: part 1 . Characterization of deformation processes in dependence on phase morphology. Polymer 1998; 39: 5689-5697.

35. Kim GM and Michler GH. Micromechanical deformation processes in toughened and particle filled semicrystalline polymers: part 2. Model representation for micromechanical deformation processes Polymer 1998; 39: 5699-5703.

36. Zuiderdein WCJ, Westzaan C, Huétink J and Gaymans RJ. Toughening of polypropylene with calcium carbonate particles. Polymer 2003; 44: 261-275.

37. Lazzeri A, Zebarjad SM, Pracella M, Cavalier K and Rosa R. Filler toughening of plastics. Part 1. the effect of surface interactions on physico-mechanical properties and rheological behaviour of ultrafine $\mathrm{CaCO}_{3}$ /high density polyethylene nanocomposites. Polymer 2005; 46: 827-844.

38. Liang JZ, Li RKY and Tjong SC. Impact fracture behavior of PP/EPDM/glass bead ternary composites. Polym Eng Sci 2000; 40: 2105-2111.

39. Liang J-Z. Impact fracture toughness of hollow glass bead filled polypropylene composites. J Mater Sci 2007; 42: 841-846. 
40. Bartczak Z, Argon AS, Cohen RE and Weinberg M. Toughness mechanism in semicrystalline polymer blends: II. High-density polyethylene toughened with calcium carbonate filler particles. Polymer 1999; 40: 2347-2365.

41. Yuan Q, Jiang W, An L and Li RKY. Effects of filler size and heat treatment on the crystallization behavior of glass bead-filled polypropylene. J Polymer Sci B Polym Phys 2005; 43: 306-313.

42. Yuan Q, Jiang W, An L, Christiansen JD and Li RKY. Competing effect between filled glass bead and induced $\beta$ crystal on the tensile properties of polypropylene/glass bead blends. J Appl Polym Sci 2005; 96: 1729-1733.

43. Jang BZ, Uhlmann DR and Sande JBV. Rubber-toughening in polypropylene. J Appl Polym Sci 1985; 30: 2485-2504.

44. Nath DCD, Bandyopadhyay S, Yu A, Blackburn D, White C and Varughese S. Isothermal crystallization kinetics of fly ash filled iso-polypropylene composite and a new physical approach. J Therm Anal Calorim 2010; 99: 423-429.

45. Nath DCD, Bandyopadhyay S, Yu AB, Blackburn D and White C. Novel observations on kinetics of nonisothermal crystallization in fly ash filled isotactic polypropylene composites. J Appl Polym Sci 2010; 115: 1510-1517. 